\title{
A periodic case study of diesel vehicle drivers exposed to diesel particulate matter in an underground coal mine
}

\author{
Sugil Lee', Ganyk Jankewicz ${ }^{1}$, Jung-Hee $\mathrm{Kim}^{2}$, Kwang Bo Chung ${ }^{+}$ \\ ${ }^{1}$ Department of Public Health, The University of Adelaide, Adelaide, SA5031, Australia \\ ${ }^{2}$ Department of Chemical Engineering, Hanseo University, Seosan 31962, Republic of Korea
}

\begin{abstract}
This study was to measure the exposure of diesel vehicle drivers to elemental carbon (EC) as an indicator of diesel particulate matter (DPM) emitted from diesel vehicles in an underground coal mine over 3 years as per NIOSH Method 5040. Our study results (range $10 \mu \mathrm{g} / \mathrm{m}^{3}-377 \mu \mathrm{g} / \mathrm{m}^{3}$ for the loader drivers, $19 \mu \mathrm{g} / \mathrm{m}^{3}-162 \mu \mathrm{g} / \mathrm{m}^{3}$ for the SMV drivers) were similar or less than previous study results (range $5 \mu \mathrm{g} / \mathrm{m}^{3}-2,200 \mu \mathrm{g} / \mathrm{m}^{3}$ ) for normal mine operations. From this study results, it appeared that the exposures decreased in the second and the third year. It is thought that the reasons for the decreased personal DPM (EC) exposures over the 3 years were related to the following recommendations; more frequent monitoring and maintenance of the diesel vehicles and their DPM filtration systems, more consistent monitoring of the mine's ventilation system and changes of work practices such as minimizing the opening of diesel vehicle windows. An educational program on adverse health effects of exposure to DPM and use of respiratory protection (P2 respirators) also assisted in minimizing driver exposure to DPM.
\end{abstract}

Keywords: Diesel particulate matter, Elemental carbon, Underground coal mine

\section{Introduction}

Diesel particulate matter (DPM) refers to a material emitted from diesel-powered machines which are commonly used in the mining industries. DPM consists of elemental carbon (EC), organic carbon (OC) and other byproducts of diesel combustion. Furthermore, irritant gases and vapours such as $\mathrm{NO}_{\mathrm{x}}, \mathrm{SO}_{\mathrm{x}}$ and aldehydes are produced. The particulates rapidly agglomerate together to form DPM aerosols typically with an aerodynamic size $<1 \mu \mathrm{m}$, smaller than occupational respirable dust aerosols which are defined with a $50 \%$ cut point of $4 \mu \mathrm{m}$. Because of its small size, airborne DPM can potentially penetrate deep into regions of human lungs and cause possible short-term and long-term adverse health effects (e.g. chronic obstructive pulmonary disease, exacerbation of asthma, chronic bronchitis, ischaemic heart disease, stroke, irritation of the nose and eyes, headache, fatigue and nausea) [1-6]. As a range of studies have indicated an increase in lung cancer mortality from exposure to diesel exhaust emissions including DPM [2, 7-8], the International Agency for Research on Cancer has classified DPM as "carcinogenic to humans" in Group 1 [9].

In an underground mine, the extent of airborne DPM distribution can vary widely due to the efficiency of air ventilation system, the use of diesel engines, the operation time of diesel engines, emission rates of DPM and the period of work activities [10]. There could also be a physical agglomeration (possibly $\geq 0.1 \mu \mathrm{m}$ ) between EC and other particulates from diesel emission and coal excavation, and that measured total carbon (TC) from diesel emission could contain an amount of coal dust, which is predominantly carbon. EC is believed to be selective for DPM sampling as there is minimal interference from other carbon sources. In order to collect EC emitted from diesel engines, NIOSH Method 5040 was developed to carry out both personal and locational airborne DPM sampling using quartz filters mounted on respirable cyclone sampling heads [11]. A commercial airborne DPM sampling cassette (SKC $37 \mathrm{~mm}$ quartz filter, part No 225-317; impactor cut point of $0.8 \mu \mathrm{m}$ at $1.7 \mathrm{~L} / \mathrm{min}$ ) has been developed. This commercial product meets NIOSH Method 5040 and the New South Wales (Australia) Mine Design Guideline (MDG-29) conditions and
This is an Open Access article distributed under the terms of the Creative Commons Attribution Non-Commercial License (http://creativecommons.org/licenses/by-nc/3.0/) which permits unrestricted non-commercial use, distribution, and reproduction in any medium, provided the original work is properly cited.

Copyright (C) 2018 Korean Society of Environmental Engineers
Received October 12, 2017 Accepted February 14, 2018

${ }^{\dagger}$ Corresponding author

Email: chemorg@hanseo.ac.kr

Tel: +82-41-660-1017 Fax: +82-41-660-1024

ORCID: 0000-0003-4100-1416 
is also suitable to be mounted on Dorr-Oliver cyclone sampling heads [10, 12-14].

There have been previous studies using the NIOSH method providing occupational exposure data for DPM in various workplaces [11,15-22] and efforts to establish occupational exposure limits for those who are exposed to airborne DPM [14, 23, 24]. However, there is still a lack of sufficient data on personal airborne DPM exposures in the mining industries and subsequent health effects to set national exposure standards.

There are currently no national legal exposure limits for DPM, however, there are several recommendations to control or minimize DPM exposure for those who are involved in the mining industry. According to the Mine Safety and Health Administration $[24,25]$ in the US, it was stated that their recommended Permissible Exposure Limit (PEL) changed from $350 \mu \mathrm{g} / \mathrm{m}^{3}$ (as TC, 2007) to $160 \mu \mathrm{g} / \mathrm{m}^{3}$ (as TC, 2008). The Health and Safety Laboratory in the UK stated that exposure to diesel engine exhaust emission in coal mines tends to be below $100 \mu \mathrm{g} / \mathrm{m}^{3}$ of EC [23]. In Australia, the NSW Department of Primary Industries (MDG-29) recommended an exposure limit (based on an 8-h work shift) of $100 \mu \mathrm{g} / \mathrm{m}^{3}$ (as submicron EC, the EC fraction typically found to constitute about $40 \%$ of the total diesel particulates mass) for NSW coal mines [14]. There is no current recommendation for DPM exposure in the Republic of Korea.

The purpose of this study was to measure occupational exposure of diesel vehicle drivers to DPM (EC), compare these results with current health guidelines and follow-up exposures after the provision of several recommendations which were suggested after the first year of monitoring. The recommendations related to the current air ventilation system, personal education, personal work practices and test frequency of diesel vehicles and DPM filtration system.

\section{Study Methods}

This study was carried out in the underground coal mine ("SC Mining Company", New Zealand) over 3 years (2011-2014). A number of diesel vehicle drivers (i.e. Loaders and Specialized Mining Vehicles (SMVs)) from two different shifts, day shift (06:00-18:00 h) and night shift (18:00-06:00 h) were monitored The same diesel vehicles were used and tested over the study period. Monitoring for DPM (EC) emitted from diesel vehicles was carried out using Dorr-Oliver cyclone sampling heads composed of commercial airborne DPM sampling cassettes (SKC $37 \mathrm{~mm}$ quartz filter, part No 225-317) as suggested by the NSW's Mine Design Guideline [14], using NIOSH Method 5040. The diesel vehicle drivers worked for $12 \mathrm{~h}$ per day for a half month (approx. $15.2 \mathrm{~d}$ per month).

All filters were allowed to be acclimatized in a desiccator with dried silica-gel for $24 \mathrm{~h}$ prior to and after sampling. They were then stored in clean petri dishes. Intrinsically safe air sampling pumps (MDA Version of Universal Pump SKC 224-PCMA4 and 224-PCMA8) were connected to sampling heads with the flow rate for respirable EC sampling set at $1.7 \mathrm{~L} / \mathrm{min}$ for the commercial airborne DPM sampling cassettes mounted on Dorr-Oliver cyclone sampling heads capturing $<1 \mu \mathrm{m}$

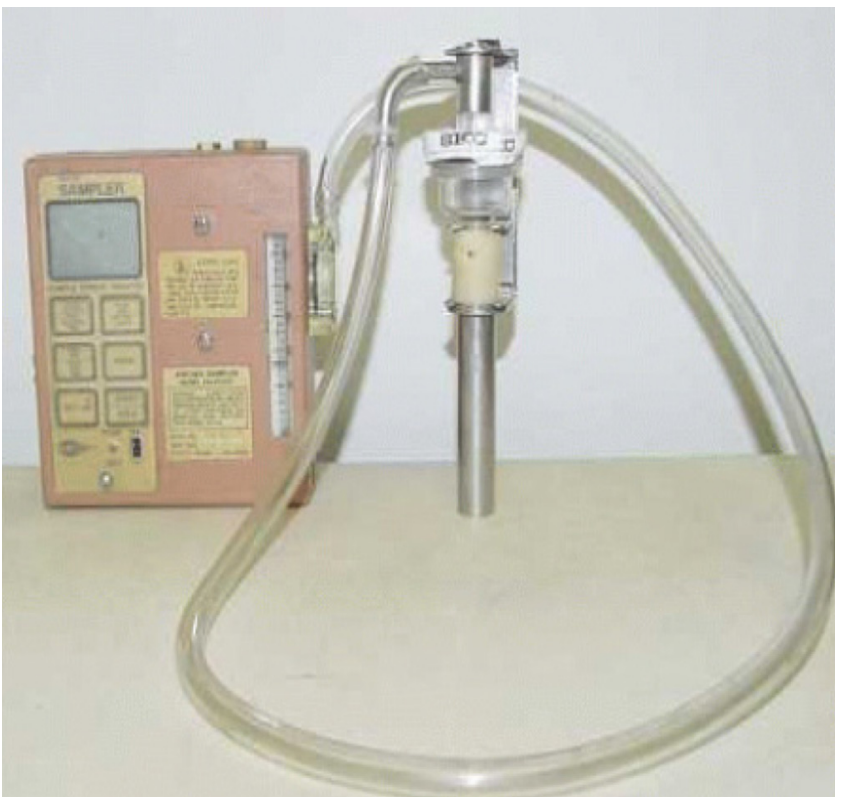

Fig. 1. A sampling cassette and a Dorr-Oliver sampling head for DPM measurements.

aerodynamic diameter (Fig. 1). The pumps' flow rates were confirmed at the beginning and the end of the sampling period to ensure the required flow rates were within the acceptable limit using a calibrated flow meter. The sampling heads were placed within the personal breathing zone (within $30 \mathrm{~cm}$ from the front hemisphere of the head) of the diesel vehicle drivers.

On completion of the airborne sampling during the day and night shifts in the underground coal mine, all sampling filters were dispatched to an accredited analytical laboratory in NSW, Australia. As per NIOSH Method 5040, thermal-optical analysis using a flame ionization detector was utilized for the analysis. The limit of detection for the sample analysis was $0.1 \mu \mathrm{g} /$ filter of EC. A Microsoft Excel program was used for statistical analysis (Geometric Mean (GM) and Standard Deviation (STD)), although there were limited numbers of samples due to the restrictive project costs and continuously changing job schedules. The data measured each year were also entered into the lognormal statistic software (IHSTST $^{\mathrm{TM}}$, American Industrial Hygiene Association - AIHA) to determine more statistical data (i.e. 95\% Upper Confidence Limit (UCL), 95\% Lower Confidence Limit (LCL), 95\% Percentile or $95^{\text {th }}$ Percentile Value, Occupational Exposure Limit (OEL), GM) (Fig. 2).

During the 3-year measurement period, walkthrough surveillance was carried out to observe the use of personal protective equipment (e.g. respirator), personal work practices (e.g. opening windows to communicate with co-workers, assisting co-workers) and the performance of the air ventilation system in the underground mine.

The exposure recommended limit by the NSW Department of Primary Industries (MDG-29) is $100 \mu \mathrm{g} / \mathrm{m}^{3}$ based the work period of $170 \mathrm{~h} / \mathrm{mon}(8 \mathrm{~h} / \mathrm{d}, 40 \mathrm{~h}$ per week), while in the study the diesel vehicle drivers worked for $12 \mathrm{~h}$ per day (approx. $15.2 \mathrm{~d}$ per month). In order to make up the working hour differ- 
ence, there was a need to adjust OEL as per MDG-29's Exposure Reduction Factors for Extended Shifts (see below).

Adjusted Exposure Limit $=$ Correction factor $\times 100 \mu \mathrm{g} / \mathrm{m}^{3}(1)$

$$
\text { correction factor }=\frac{170(h / m o n)}{H \times D(h / m o n)}
$$

Here, H: Average number of hours worked in a day $(\mathrm{h} / \mathrm{d})$ D: Average number of days worked in a month $(\mathrm{d} / \mathrm{mon})$

The adjusted OEL for $12 \mathrm{~h}$ per day for a half month (approx. $15.2 \mathrm{~d}$ per month) is $93 \mu \mathrm{g} / \mathrm{m}^{3}$ of EC.

\section{Results}

Two kinds of diesel vehicles (i.e. Loaders and SMVs) were chosen for this study. In order to reduce or remove DPM while the diesel vehicles were operated, each diesel vehicle had either one of two control systems; 1) diesel particulate filters, 2) water filtration system using diesel oxidation catalyst. Loaders were used to deliver coal products and other tools/equipment. SMVs were mainly used to transport miners in and out of the underground mine.

An air ventilation system was installed to provide continuous negative pressure reducing excessive environmental factors such as airborne contaminants, humidity and heat emitted from diesel vehicle operation and coal excavation in the underground mine. This allowed outside fresh and dried air to come in through the outside tunnel entry. As the use of the air ventilation system alone as a control for DPM exposure may not provide sufficient protection, wearing personal respiratory protection (i.e. ESKO Safety Gear, PROMESH- P2 type with valve and active carbon filter; 3M, Disposable Air Purifying respirator with P2 type particulate filter) was recommended to the diesel vehicle drivers working in this mine. During the first and second years, it was noted that all diesel vehicle drivers who were subjects in this study did not wear their respirators while they were driving the diesel vehicles. In the third year, it was observed that up to $33 \%$ of the loader drivers and $60 \%$ of the SMV drivers were wearing respirators while in their diesel vehicles.

During the first year, it was observed that the diesel vehicle drivers frequently opened their vehicle windows and got in/out of the vehicles to communicate with co-workers while underground. They were also occasionally involved in other tasks supporting other miners, vehicle operators and co-workers, without wearing the respirators provided. After the completion of the personal airborne DPM (EC) measurements in the first year, several recommendations as below, were provided to the diesel vehicle drivers. During the second and third years, further observation was performed to check whether these recommendations were being implemented.

Table 1. Personal Airborne EC Exposure Monitoring Results during the 3 Years

\begin{tabular}{|c|c|c|c|c|c|c|}
\hline Measurement & Shift & $\begin{array}{l}\text { Sampling } \\
\text { time period }\end{array}$ & $\begin{array}{l}\text { Number of } \\
\text { samples }\end{array}$ & $\begin{array}{c}\text { EC-Statistics }(\mathrm{GM} \pm \text { STD) } \\
\left(\text { Min-Max) }\left(\mu \mathrm{g} / \mathrm{m}^{3}\right)\right.\end{array}$ & $\begin{array}{l}\text { Respirator } \\
\text { use }\end{array}$ & DPM control system \\
\hline \multicolumn{7}{|c|}{ Loaders } \\
\hline \multirow{2}{*}{$1^{\text {st }}$ year } & Day & 06:00-18:00 h & 6 & $184 \pm 112(104-377)$ & NIL & $\begin{array}{l}\text { DPM filter x } 3(50 \%), \\
\text { Water filter x } 3(50 \%)\end{array}$ \\
\hline & Night & 18:30-06:30 h & 4 & $105 \pm 34(82-156)$ & NIL & DPM filter x 4 (100\%) \\
\hline \multirow{2}{*}{$2^{\text {nd }}$ year } & Day & $06: 35-17: 30 \mathrm{~h}$ & 3 & $36 \pm 24(22-67)$ & NIL & DPM filter x 3 (100\%) \\
\hline & Night & 18:30-06:10 h & 5 & $86 \pm 62(17-190)$ & NIL & $\begin{array}{l}\text { DPM filter x } 2 \text { (40\%), } \\
\text { Water filter x } 3(60 \%)\end{array}$ \\
\hline \multirow{2}{*}{$3^{\text {rd }}$ year } & Day & 06:00-18:00 h & 3 & $34 \pm 46(10-100)$ & $33 \%$ & DPM filter x 3 (100\%) \\
\hline & Night & 18:00-06:00 h & 4 & $81 \pm 49$ (46-159) & $25 \%$ & DPM filter x 4 (100\%) \\
\hline \multicolumn{7}{|c|}{ SMVs } \\
\hline $1^{\text {st }}$ year & Day & 06:50-14:30 h & 3 & $85 \pm 58(58-162)$ & NIL & Water filter x $3(100 \%)$ \\
\hline $2^{\text {nd }}$ year & Day & $06: 35-17: 30 \mathrm{~h}$ & 3 & $68 \pm 15(53-83)$ & NIL & Water filter x $3(100 \%)$ \\
\hline $3^{\text {rd }}$ year & Day & 06:00-18:00 h & 5 & $57 \pm 30(19-91)$ & $60 \%$ & Water filter x 5 (100\%) \\
\hline \multicolumn{4}{|c|}{ MDG-29's PEL (DPI, 2008) } & \multicolumn{3}{|c|}{$93 \mu \mathrm{g} / \mathrm{m}^{3}$ (Adjusted for $12 \mathrm{~h} / \mathrm{d}, 15.2 \mathrm{~d} / \mathrm{mon}$ ) } \\
\hline
\end{tabular}

*NOTE: GM (Geometric Mean), STD (Standard Deviation) 

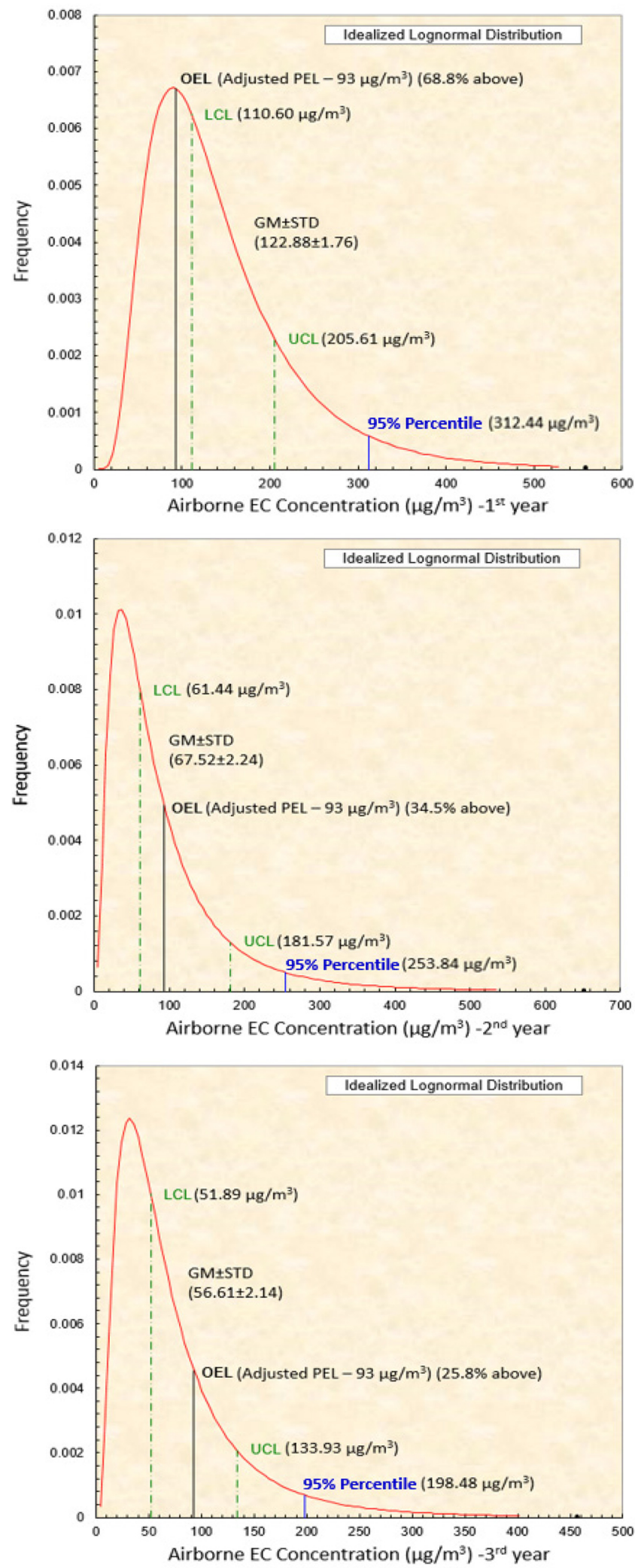

Fig. 2. Probability distribution of values of personal airborne EC concentrations measured during the 3 years.
1) More frequent in-house exhaust emission testing (i.e. gases, particulates including DPM) for the diesel engines and filtration performance test for DPM filters, at least once a week or twice per month.

2) More attention to be paid to monitoring of the air ventilation system to ensure sufficient negative pressure to minimize airborne contaminants.

3) Improving the drivers' work practices, such as using a communication device for communication with co-workers instead of frequently opening the diesel vehicle windows underground.

4) Providing more educational programs to workers regarding potential adverse health effects caused by the exposure to DPM and the importance of wearing the respirators provided.

Measured personal airborne DPM (EC) exposures for the day and night shift diesel vehicle drivers are shown in Table 1.

In the case of the loader drivers, their personal airborne DPM (EC) exposures (GMs) were $184 \mu \mathrm{g} / \mathrm{m}^{3}$ (Day shift) and $105 \mu \mathrm{g} / \mathrm{m}^{3}$ (Night shift) measured in the first year, which were higher than the adjusted exposure limit $\left(93 \mu \mathrm{g} / \mathrm{m}^{3}\right)$. In the second year, personal airborne DPM (EC) exposures (GMs) were $36 \mu \mathrm{g} / \mathrm{m}^{3}$ (Day shift) and $86 \mu \mathrm{g} / \mathrm{m}^{3}$ (Night shift). In the third year, the monitoring results were $34 \mu \mathrm{g} / \mathrm{m}^{3}$ (Day shift) and $81 \mu \mathrm{g} / \mathrm{m}^{3}$ (Night shift). Both second and third year results were lower than the adjusted exposure limit $\left(93 \mu \mathrm{g} / \mathrm{m}^{3}\right)$. However, there was no consistency of different DPM exposures between the day shift and night shift in each year.

The SMV drivers' personal airborne DPM (EC) exposures in the day shift were $85 \mu \mathrm{g} / \mathrm{m}^{3}$ in the first year, $68 \mu \mathrm{g} / \mathrm{m}^{3}$ in the second year and $57 \mu \mathrm{g} / \mathrm{m}^{3}$ in the third year, all lower than the adjusted exposure limit $\left(93 \mu \mathrm{g} / \mathrm{m}^{3}\right)$.

According to all raw data collected over the 3 years, data (8/10 exposures of the loader drivers, $1 / 3$ exposure of the SMV drivers) of the diesel vehicle drivers' personal airborne DPM (EC) exposures were higher than the adjusted exposure limit $\left(93 \mu \mathrm{g} / \mathrm{m}^{3}\right)$ in the first year, but their exposures decreased in the second and third years. This reduction in personal airborne DPM (EC) exposure was likely due to implementation of recommendations suggested in the first year.

Information on use of respirators and diesel filtration systems are included in Table 1. It was noted that no diesel vehicle driver wore the respirators provided in the first and second year, but $25-60 \%$ of the diesel drivers were wearing the respirators in the third year. It was also noted that either DPM filters or water filter systems were installed on the each of the diesel vehicles.

In Fig. 2, statistical results (i.e. 95\% UCL, 95\% LCL, 95\% Percentile, OEL values, GMs) for each year are shown as lognormal distributions for all drivers. Ninety-five percent UCL values decreased from $205.6 \mu \mathrm{g} / \mathrm{m}^{3}$ in the first year to $133.9 \mu \mathrm{g} / \mathrm{m}^{3}$ in the third year, and $95 \%$ LCL values decreased from 110.6 $\mu \mathrm{g} / \mathrm{m}^{3}$ in the first year to $51.9 \mu \mathrm{g} / \mathrm{m}^{3}$ in the third year. Ninety-five percentile values decreased from $312 \mu \mathrm{g} / \mathrm{m}^{3}$ in the first year to $198 \mu \mathrm{g} / \mathrm{m}^{3}$ in the third year. The percentages of exposures 
Table 2. EC Exposure Assessment Results from Previous Study Results Done for Underground Mining Industries in Australia and USA

\begin{tabular}{lcccc}
\hline \multicolumn{1}{c}{ Author(s) } & Published year & EC exposures $\left(\mu \mathrm{g} / \mathbf{m}^{\mathbf{3}}\right.$ ) & Mining industries & Country \\
Pratt et al. [15] & 1993 & $\begin{array}{c}5-400 \text { (normal operation) } \\
400-600 \text { (increasing workloads) }\end{array}$ & Coal mines & Australia \\
\hline Pratt et al. [16] & 1997 & $100-2,200$ & Coal mines & Coal mines \\
\hline Joint Coal Board [17] & 1999 & $10-370$ & Mustralia \\
\hline Rogers and Davies [18] & 2001 & $10-420$ & Non-metal miferous mines & Australia \\
\hline Coble et al. [21] & 2010 & $31-488$ & USA \\
\hline
\end{tabular}

over the OEL value $\left(93 \mu \mathrm{g} / \mathrm{m}^{3}\right)$ decreased from $68.8 \%$ in the first year to $25.8 \%$ in the third year. The yearly GM values also decreased from $122.9 \mu \mathrm{g} / \mathrm{m}^{3}$ in the first year to $56.6 \mu \mathrm{g} / \mathrm{m}^{3}$ in the third year.

\section{Discussion}

Measurement of personal airborne DPM (EC) exposure level in the mining industry is needed to compare exposures against recommended guidelines and to provide more data to assist in the establishment of national occupational exposure limits for those who are working with or around diesel vehicles, although further research is needed to ensure that these guidelines or standards are sufficiently protective of adverse health effects [26].

Using commercial DPM cassettes and Dorr-Oliver sampling heads as per NIOSH Method 5040, measurements were carried out for the diesel vehicle drivers (i.e. loaders and SMV drivers) involved in day and night shifts in an underground coal mine in New Zealand over 3 years. In order to minimize personal exposures to DPM (EC) while driving the diesel vehicles (i.e. loaders, SMVs), several recommendations were suggested after the completion of the measurements in the first year. In the following years, this study investigated the effectiveness of these recommendations. During the study period, walkthrough surveillance was also carried out to observe work practices (i.e. wearing the respiratory protectors provided, opening of vehicle windows, assisting co-workers), diesel vehicle maintenance including DPM filtration system and management of the air ventilation system.

As seen in Table 1, the loader drivers' personal airborne DPM (EC) exposures were between $82 \mu \mathrm{g} / \mathrm{m}^{3}-377 \mu \mathrm{g} / \mathrm{m}^{3}$ in the first year, with reduction in the exposures in the second and third years ranging from $17 \mu \mathrm{g} / \mathrm{m}^{3}-190 \mu \mathrm{g} / \mathrm{m}^{3}$ and $10 \mu \mathrm{g} / \mathrm{m}^{3}-159$ $\mu \mathrm{g} / \mathrm{m}^{3}$, respectively. It was noted that the exposures between the two shifts were different possibly due to daily work schedule for coal excavation and usage time of the diesel vehicles. In the case of the SMV drivers, their personal airborne DPM (EC) exposures were between $58 \mu \mathrm{g} / \mathrm{m}^{3}-162 \mu \mathrm{g} / \mathrm{m}^{3}$ in the first year. After that, the exposures in the second and third years decreased to $19 \mu \mathrm{g} / \mathrm{m}^{3}-91 \mu \mathrm{g} / \mathrm{m}^{3}$ which were below the adjusted occupational exposure limit of $93 \mu \mathrm{g} / \mathrm{m}^{3}$. In Table 1, it can be seen that the exposures of the day shift SMV drivers were higher than that of the day shift loader drivers. The reason for these higher exposures could be related to more frequent involvement in assisting other miners and co-workers, who may have been involved with vehicle maintenance, cleaning or moving construction materials.

Our study results are similar to previous study results shown in Table 2, even though our study had limited sampling numbers.

A statistical approach using lognormal distribution for the yearly exposure data was performed and their results are shown in Fig. 2. According to these results, even though there were limited numbers of samples taken for statistics due to the restrictive project costs and altered job schedules, it appears that all personal DPM (EC) exposures were reducing over the period of our study. In addition, the percentages of the exposures over the adjusted OEL value $\left(93 \mu \mathrm{g} / \mathrm{m}^{3}\right.$ ) also decreased from $68.8 \%$ to $25.8 \%$ over the 3 years. Reasons for the decreased exposures over the period of our study could be related to the effectiveness of the recommendations (i.e. changing personal work practices, improved management of the air ventilation system and more frequent examination and maintenance of diesel vehicles and DPM filters). In particular, it is thought that the most effective recommendation to minimize airborne DPM (EC) exposures during this study period would be more frequent in-house DPM filtration performance testing and diesel vehicle maintenance. Here, the in-house DPM filtration performance testing is for diesel particulate exhaust emissions including smoke and gaseous emissions after the DPM filters (i.e. diesel particulate filters and water filtration system) installed in the diesel vehicles. It was recommended these tests be carried out at least once a week or 2 times per month, instead of once a month as suggested by the NSW's Mine Design Guideline (MDG-29) [14].

\section{Conclusions}

Our study monitored diesel vehicle drivers (i.e. loaders, SMVs) for airborne breathing zone DPM (EC) exposures and comparison of these results to current guidelines. According to our study results, it appeared that the exposures were decreasing from the second year and while the most of the results in the first year were above the adjusted occupational limit $\left(93 \mu \mathrm{g} / \mathrm{m}^{3}\right)$, almost all of the results of the next two years were below this limit, possibly due to implementation of our recommendations suggested in the first year. From the results in this study, while exposures may be able to be controlled to below current guidelines using engineering control methods, the use of respirators and continuing educational programs should result in a lower 
risk of health effects pending further improvements in engineering controls. Even though this study has limitations such as lack of the sampling numbers, assessment of respirator fit, no other diesel emission (vapour, gas) measurement and no health survey results, further monitoring for other diesel pollutants (i.e. gaseous and particulates) from underground mine industries should be carried out. A health survey including information on respiratory symptoms is a suggested approach for better understanding on miners' health symptoms related to diesel emissions and probability of cancer.

\section{References}

1. Sydbom A, Blomberg A, Parnia S, Stenfors N, Sandstrom T, Dahlen S. Health effects of diesel exhaust emissions. Eur. Respir. J. 2001;17:733-746.

2. Diesel particulate matter exposure of underground metal and nonmetal miners. Mine Safety and Health Administration, 30 CFR Part 57, US Federal Bulletin 50; 2001.

3. Davies B. The efficiency of diesel exhaust filters used in underground coal mines. In: 20th Annual Conference on Australian Institute of Occupational Hygienists; 30 Nov 4 Dec 2002; Geelong VIC. p. 63-67.

4. Morawska L, Hofman W, Hitchins-Loveday J, Swanson C, Mengersten K. Experimental study of the deposition of combustion aerosol in the human respiratory tract. J. Aerosol Sci. 2005;36:939-957.

5. Hart J, Laden F, Eisen E, Smith T, Garshick E. Chronic obstructive pulmonary disease mortality in railroad workers. Occup. Environ. Med. 2009;66:221-226.

6. Rissler J, Swietlicki E, Bengtsson A, et al. Experimental determination of deposition of diesel exhaust particles in the human respiratory tract. J. Aerosol Sci. 2012;48:18-33.

7. Brown A, Christie D, Taylor R, Seccomble M, Coates M. The occurrence of cancer in a cohort study of New South Wales coal miners. Aust. N. Z. J. Public Health 1997;21:29-32.

8. Bae H, Park J. A review on diesel engine exhaust and lung cancer risks. J. Environ. Health Sci. 2012;38:277-290.

9. Diesel engine exhaust carcinogenic. International Agency for Research on Cancer, Press release No 213, 2012 [cited 23-May 2017]. Available from: http://www.iarc.fr/en/media-centre/pr/2012/pdfs/pr213_E.pdf IARC.

10. Diesel aerosols and gases in underground mines: Guide to exposure assessment and control. RI 9687 Report of Investigations/2011, Dept of Health and Human Services, National Institute of Occupational Safety and Health, NIOSH Publication 2012-101.

11. Diesel particulate matter (as elemental carbon). NIOSH manual of analytical methods 5040. 4th ed. National Institute of Occupational Safety and Health, NIOSH Publication 2003-154.

12. Noll J, Timko R, McWilliams L, Hall P, Haney R. Sampling results of the improved SKC diesel particulate matter cassette. J. Occup. Environ. Hyg. 2005;2:29-37.

13. Noll J, Mischler S, Schnakenberg G, Bugarski A. Measuring diesel particulate matter in underground mines using sub microne elemental carbon as a surrogate. Proceedings of the $11^{\text {th }}$ U.S./north American Mine Ventilation Symposium. University Park, Pennylvania, 5-7 June 2006. In: Mutmansky J, Ramani R, eds. London: Taylor \& Francis Group. p. 105-110.

14. Guideline for the management of diesel engine pollutants in underground environments - MDG 29. NSW Department of Primary Industries Australia; 2008.

15. Pratt S, Todd J, Davies B, Rogers A. Diesel particulate exhaust emissions, worker exposure and control technology in some Australian underground mines. In: Minesafe International, Chamber of Mines and Energy of Western Australia, Perth, WA; 1993.

16. Pratt S, Grainger A, Todd J, Meena G, Rogers A. Davis B. Evaluation and control of employee exposure to diesel particulate at several Australian coal mines. Appl. Occup. Environ. Hyg. 1997;12:1032-1040.

17. Diesel particulate in coal mines - Questions \& answers. 1st ed. The Joint Coal Board 1999, NSW, Australia; 1999.

18. Rogers A, Davies B. Diesel particulate (soot) exposures and methods of control in some Australian underground metalliferous mines. Short Course Notes, In: 19th Annual Conference, Australian Institute of Occupational Hygienists (AIOH). 1-5 December 2001; Tullamarine, Vic.

19. Cohen H, Borak J, Hall T, Sirianni G, Chemerynski S. Exposure of miners to diesel exhaust particulates in underground nonmetal mines. Am. Ind. Hyg. Assoc. J. 2002;63:651-658.

20. Noll J, Birch M. Evaluation of SKC DPM cassettes for monitoring diesel particulate matter in coal mines. J. Environ. Monit. 2004;6:973-978.

21. Coble J, Stewart P, Vermeulen R, et al. The diesel exhaust in miners study: II. Exposure monitoring surveys and development of exposure groups. Ann. Occup. Hyg. 2010;54: 747-761.

22. Stewart P, Coble J, Vermeulen R, et al. The diesel exhaust in miners study: I. Overview of the exposure assessment process. Ann. Occup. Hyg. 2010;54:728-746.

23. Controlling and monitoring exposure to diesel engine exhaust emissions in coal mines. HSL/2005/55, Health and Safety Laboratory, UK. HSL; 2005.

24. Exposure of underground miners to diesel exhaust. Mine Safety and Health Administration, 30 CFR Part 57,70,72 and 75, US Federal Register 81(110); 2016.

25. Diesel particulate matter exposure of underground metal and nonmetal miners. Mine Safety and Health Administration, 30 CFR Part 57, US Federal Register 73(98); 2008.

26. Greim H, Hartwig A, Levy L, et al. SCOEL/OPIN/403 diesel engine exhaust. Opinion from the Scientific Committee on Occupational Exposure Limits, European Commission; 2016. 